\title{
Effects of narrow linear clearings on movement and habitat use in a boreal forest mammal community during winter
}

\author{
Colin A. Pattison ${ }^{\text {Corresp.. }}{ }^{1,2}$, Carla P Catterall ${ }^{1}$ \\ ${ }^{1}$ School of Environment and Science, Environmental Futures Research Institute, Griffith University, Nathan, QLD, Australia \\ 2 MacPhail School of Energy, SAIT Polytechnic, Calgary, AB, Canada \\ Corresponding Author: Colin A. Pattison \\ Email address: colin.pattison@sait.ca
}

Linear clearings for human activities cause internal fragmentation of otherwise intact native forest, with many potential impacts on wildlife. Across a boreal forest region of some $4,000 \mathrm{~km}^{2}$, we investigated how movements and habitat use of ecologically different mammal species are affected by narrow (about $8 \mathrm{~m}$ ) seismic line clearings associated with fossil fuel extraction, which form extensive networks many kilometres long. We conducted nine repeat snow track surveys during three winters at 14 pairs of one-kilometer transects, each comprising one transect along the seismic line and a second running perpendicular into adjacent forest. Data for 13 individually-analysed mammal taxa (species or sets of closely related species) and five mammal groups, categorized based on body size-diet combinations, showed that movements across transects were either unaffected by seismic line clearings (relative to continuous forest) or restricted only slightly. However, these clearings were favoured for linear travel by most species and body size-diet groups (excepting small mammals). The strength of this preference varied in a manner consistent with species' differing needs to move long distances (associated with their energetic requirements): large predators $>$ large herbivores $>$ mid-sized predators $>$ mid-sized herbivores > small mammals. In terms of overall habitat use, large-bodied predators (e.g., wolves and coyotes) strongly selected seismic line clearings over forest, medium-sized predators (e.g., mustelids) and medium-sized herbivores (e.g., hares and squirrels) preferred forest, and neither large herbivores nor small mammals had a clear habitat preference. Consequently, there was a net shift in both species and trophic composition within the seismic line, in favour of large predators and away from medium-sized predators and herbivores. Given the high regional seismic line density $\left(1.9 \mathrm{~km} / \mathrm{km}^{2}\right)$ such shifts are likely to have complex ecological consequences, of currently unknown magnitude. 
1 Effects of narrow linear clearings on movement and habitat use in a boreal forest mammal

2 community during winter

3 Colin A. Pattison, Carla P. Catterall

4 C.A. Pattison (Corresponding author)

5 School of Environment and Science, Environmental Futures Research Institute

6 Griffith University

7 Nathan, QLD, Australia.

8 Current Address: SAIT Polytechnic, MacPhail School of Energy, Calgary, AB, Canada

9 Email: colin.pattison@,sait.ca

10 Ph: 00+1+403-210-4065.

11 C.P. Catterall

12 School of Environment and Science, Environmental Futures Research Institute

13 Griffith University

14 Nathan, QLD, Australia.

\section{ACKNOWLEDGEMENTS}

Thanks to L. Stone, D. Soon, G. Gerelus, J. Richards, M. Lord, V. Stockdale, E. Neilson, L.

Kemmer, B. Cress, A. Cardinal, C. Davison for help with data collection, and to Pat Dale and Michael Quinn for input into study design.

\section{Abstract}

Linear clearings for human activities cause internal fragmentation of otherwise intact native

forest, with many potential impacts on wildlife. Across a boreal forest region of some 4,000 $\mathrm{km}^{2}$,

we investigated how movements and habitat use of ecologically different mammal species are

affected by narrow (about $8 \mathrm{~m}$ ) seismic line clearings associated with fossil fuel extraction,

which form extensive networks many kilometres long. We conducted nine repeat snow track surveys during three winters at 14 pairs of one-kilometer transects, each comprising one transect along the seismic line and a second running perpendicular into adjacent forest. Data for 13 individually-analysed mammal taxa (species or sets of closely related species) and five mammal groups, categorized based on body size-diet combinations showed that movements across 
31 transects were either unaffected by seismic line clearings (relative to continuous forest) or

32 restricted only slightly. However, these clearings were favoured for linear travel by most species

33 and body size-diet groups (excepting small mammals). The strength of this preference varied in a

34 manner consistent with species' differing needs to move long distances (associated with their

35 energetic requirements): large predators $>$ large herbivores $>$ mid-sized predators $>$ mid-sized

36 herbivores > small mammals. In terms of overall habitat use, large-bodied predators (e.g., wolves

37 and coyotes) strongly selected seismic line clearings over forest, medium-sized predators (e.g.,

38 mustelids) and medium-sized herbivores (e.g., hares and squirrels) preferred forest, and neither

39 large herbivores nor small mammals had a clear habitat preference. Consequently, there was a

40 net shift in both species and trophic composition within the seismic line, in favour of large

41 predators and away from medium-sized predators and herbivores. Given the high regional

42 seismic line density $\left(1.9 \mathrm{~km} / \mathrm{km}^{2}\right)$ such shifts are likely to have complex ecological

43 consequences, of currently unknown magnitude. 


\section{INTRODUCTION}

Long and narrow clearings for human activities divide large forest tracts into multiple smaller patches, leading to a range of potential impacts on animals' spatial behavior, movements and relationships (Forman 1995b; Benitez-Lopez et al. 2010). For example, development associated with fossil fuel extraction is increasingly creating extensive networks of linear clearings such as roads, recreation trails, powerlines, pipelines, and seismic exploration lines (Butt et al. 2013). In particular, ground-active mammals are likely to be strongly impacted, because these linear forest clearings are more open than, and very different from, intact forest vegetation (Forman 1995a; Haddad et al. 2003).

Research into the impacts of linear clearings on terrestrial mammals has largely focused on roads (Trombulak \& Frissell 2000), but the nature of impact potentially differs according to both the type of clearing and the species or ecological characteristics of particular mammals. For example, road clearings are distinguished by high intensities of vehicular movements and of human use, which induce their avoidance by some animals (Coffin 2007) but any type of linear clearing could present a barrier to crosswise movement, irrespective of the level of human usage (McGregor et al. 2008), because some species simply avoid clearings, even in naturally patchy forests (e.g. boreal, Hodson et al. 2010). If cleared ground is a barrier to movement, or if areas adjacent to the forest edge are avoided, forests become functionally fragmented (Smith \& Smith 2009) for affected mammals. Indeed, linear forest clearings are commonly expected to impede movements, especially for smaller mammals, due to their smaller home ranges and limited capacity for movement (Oxley et al. 1974; Goosem 2002; Peter et al. 2013). However, some mammal species preferentially use both road verges and non-road linear clearings because they provide either movement corridors (Gese et al. 2013; Tigner et al. 2014), or particular food 
68

69

70

71

72

resources (Morelli et al. 2014). Such preferential use for travel has been observed in some large predators, and can then have further indirect effects on other mammal species which avoid areas near linear clearings to reduce the risk of predation (Dyer et al. 2001). Given this diversity of potential responses, evidence remains sparse about how various different mammal species within a forest community are impacted by non-road linear clearings.

Species that differ in functional characteristics such as body size and diet could be expected to vary predictably in their type of response to non-road linear clearings. For example, larger bodied mammals move over relatively larger areas to meet their metabolic requirements (Swihart et al. 1988), predators move the greatest distances (Garland 1983; Gittleman 1985), and mammals moving between high quality forage and hunting areas in snow-covered areas adapt their movement behavior to decrease energy expenditure (Telfer \& Kelsall 1984; Potapov et al. 2011). Obstacle-free clearings that extend over long distances are well suited for energetically efficient long-distance linear travel. However, previous research has mainly focused on either single species or subsets of functionally similar species (Harmsen et al. 2010; Gese et al. 2013; Tigner et al. 2014). Assessments and comparisons of responses to non-road linear clearings by different mammals within the same community have been lacking.

This study aims to determine how non-road linear forest clearings affect different species, of varying sizes and trophic levels, that comprise the diverse mammal community characteristic of boreal forest. Within a region where linear seismic clearings ( $<10 \mathrm{~m}$ wide) have been established in extensive networks to explore for underground oil and gas deposits (Pattison et al. 2016), we placed replicated paired transects in forest and along seismic lines, in which mammal movements and habitat use were assessed in winter using snow track surveys. We test hypotheses that linear clearings differ from forest in any of: crosswise movements, longitudinal 
91 travel, and overall usage, for different individual species and for groups of mammals based on

92 body size-diet (body size-diet hereafter) combinations that reflect differences in species'

93 energetic needs and ecological relationships. We evaluate the possible role of snow

94 supportiveness as a contributor to observed impacts. We also assess the extent to which these

95 response patterns vary among species and body size-diet groups, and whether the relative

96 propensities of different body size-diet groups to travel preferentially along linear clearings

97 corresponds with their expected energy requirements for movement and thus progressively

98 decrease from large predators to large herbivores to mid-sized predators to mid-sized herbivores

99 to small mammals.

100 METHODS

101 Study Area

102 The boreal forest study region was located in the foothills of the Rocky Mountains, west of

103 Calgary, Alberta, Canada, at 1,150-1,802 m elevation, across an area of 4,022 $\mathrm{km}^{2}\left(50.9-52.1^{\circ} \mathrm{N}\right.$,

104 114.7-115.2 ${ }^{\circ} \mathrm{W}$; see Pattison et al. 2016). Occupying a transition zone between mountains and

105 grassland, the region supports a diverse mammalian fauna comprising 25-30 species that are

106 typically active in winter, including shrews (Insectivora), rodents (Rodentia), lagomorphs

107 (Lagomorpha), ungulates (Artiocactyla) and carnivores (Carnivora; ASRD 2000). The mean

108 daily temperature in winter is $-6^{\circ} \mathrm{C}$, with mean annual snowfall of $186 \mathrm{~cm}$, falling on an average

109 of 6.5 days/month during October-April (Environment Canada 2009).

110 The dominant native vegetation type is coniferous forest in which important species

111 (Archibald et al. 1996) include pine (Pinus contorta), spruce (Picea glauca, P. mariana), fir

112 (Abies lasiocarpa, A. balsamea) and tamarack (Larix laricina); also present are some stands of 
113 deciduous forest, dominated by poplar (Populus balsamifera), aspen (Populus tremuloides) and

114 birch (Betula papyifera). At the time of the study, landscape cover in the study region was $67 \%$

115 coniferous forest (in which the cover of tree crowns was at least $60 \%$ ), $4 \%$ deciduous forest and

$11629 \%$ non-forest vegetation including cleared former forest with some agricultural areas (Pattison

117 et al. 2016). Some forest areas were in use for commercial timber extraction, and the study

118 region therefore included a mosaic of various successional stages of regeneration. Forested areas

119 were also criss-crossed by seismic lines and other linear infrastructure clearings connected with

120 exploration for, and extraction of, below-ground oil and gas. Clearings for seismic lines

121 (henceforth also termed SLs) were about $8 \mathrm{~m}$ wide and many kilometers long, and formed

122 extensive networks. They occupied about $1.1 \%$ of otherwise forested land, at an average density

123 of $1.9 \mathrm{~km} / \mathrm{km}^{2}$; the wider linear clearings for powerlines, pipelines and roads, together accounted

124 for $1.8 \%$, and $0.8 \mathrm{~km} / \mathrm{km}^{2}$ (Pattison et al. 2016; Figure 1).

125 \#insert Figure 1 approximately here\#

\section{Study design}

127 We surveyed mammals in 14 replicate $1.0 \mathrm{~km} \mathrm{X} 1.0 \mathrm{~km}$ sites (Alberta, Tourism, Parks \&

128 Recreation, approval 11-014, 12-087), dispersed across a study region that extended $142 \mathrm{~km}$

129 north-south and $28 \mathrm{~km}$ east-west. Each site contained a pair of transects (SL and forest transects),

130 each partitioned into ten $0.1 \mathrm{~km}$ sub-transects (Figure 1). Site selection was constrained by

131 logistic and safety concerns. Sites were positioned to obtain adequate replication, while also

132 maximizing their: spatial dispersion (mean nearest neighbour distance $6.0 \mathrm{~km}$, SE 0.8 ; range 3.2

133 to $12.1 \mathrm{~km})$; separation from both roads $(>100 \mathrm{~m})$ and areas of timber extraction $(>500 \mathrm{~m})$; and

134 amount of coniferous forest cover (apart from SL clearings). Average forest cover (mean 98.4\%, 
135 SE 1.4\%) was affected by two sites that contained areas from which timber had been extracted

136 during $1990-2000$ (3\% and 20\% of sites' areas), where trees had regrown to $6 \mathrm{~m}$ or more in

137 height before this study commenced.

Each SL transect was aligned along a seismic line and occupied its complete width,

139

140

141

142

143

144

145

146

147

148

149

150

151

152

153

154

155

156

averaging $7.7 \mathrm{~m}$ (SE 0.4, range 6.3-11.2; $\mathrm{n}=14$ sites). SLs were inaccessible to conventional

motor vehicles, but some had been widened by off-road vehicle activity, while infrequently-used

SLs were narrowed by tree and shrub encroachment. Each forest transect was equal in width to its paired SL transect, and was placed approximately perpendicular to it (depending on local terrain), extending into the forest (Figure 1). Half of the forest transects were oriented north to south and half east to west. Although established in continuous forest as far as possible, eight forest transects were unavoidably crossed by SLs, accounting for $0.9 \%$ on average $(\mathrm{SE}=0.3 \%$, range $0-4 \%, n=14$ transects) of their areas.

In the area surrounding site transects (1.5 $\mathrm{km}$ in all directions), SL density averaged 2.6 $\mathrm{km} / \mathrm{km}^{2}$ (SE 0.3, range 0.9-4.4, $\mathrm{n}=14$ ). Other linear clearings (roads, powerlines, pipelines) averaged $1.0 \mathrm{~km} / \mathrm{km}^{2}(\mathrm{SE} 0.2$, range $0.3-2.5)$ in density.

Each transect was surveyed (details below) for mammals and snow conditions nine times over three winters (twice in December 2010 to April 2011, three times in December 2011 to April 2012, four times in November 2012 to April 2013). Surveys of both transects within each site were completed on the same day and generally one or two sites were surveyed per day. Repeat surveys were not conducted until sufficient snow had fallen to completely obliterate tracks recorded in the previous survey. Transects were surveyed by either one (2012-2013) or two observers (2010-2011) travelling on foot. 


\section{Mammal surveys}

158 During each survey, all mammal tracks on each sub-transect were classified by trained 159 observers using reference materials (Forrest 1988), to the finest possible taxon (Table 1); usually

160 to species but sometimes to genus, and for voles to several related genera; in some cases

161 identification involved backtracking up to $100 \mathrm{~m}$. Each taxon was also assigned to one of five

162 body size-diet groups based on combinations of body weight and diet: large predators ( $>10 \mathrm{~kg})$,

163 large herbivores $(>94 \mathrm{~kg})$, mid-sized predators $(0.13-9.1 \mathrm{~kg})$, mid-sized herbivores $(0.25-1.5 \mathrm{~kg})$, 164 and small mammals $(\leq 20 \mathrm{~g}$; Table 1$)$.

165 \# insert Table 1 approximately here\#

166 Each identified track was classified (Figure 1) as either a crossing, approach or linear travel.

167 Crossings completely spanned a transect width within a longitudinal distance of $<10 \mathrm{~m}$, having 168 originated within the adjacent forest. Approaches also originated within adjacent forest, but they

169 stopped and returned to the forest on the entry side at or slightly beyond the transect edge. Linear

170 travels entered a transect either from adjacent forest or in a clearing at one end, and they

171 continued in a straight or diagonal linear path along the transect for at least $10 \mathrm{~m}$ (measured

172 parallel to the transect edge) before entering the forest on either side or continuing past the

173 transect end. Linear travel distance (m) was then measured as the net resulting longitudinal

174 displacement (within the transect and parallel to its edge).

175 For each taxon and each body size-diet group during each of the nine repeat surveys, we 176 calculated the numbers of crossings (C), approaches (A), and the total linear travel distance (D),

177 for each sub-transect (100 m length), and for each transect $(1.0 \mathrm{~km})$. Three further measurements 178 of individuals' responses to the presence of each transect were then calculated. First, crossing 
179 propensity was calculated as $100 \mathrm{C} /(\mathrm{C}+\mathrm{A})$, i.e. the percent of direct approaches from the adjacent

180 forest habitat that resulted in a crossing movement. Second, linear travel propensity was

181 calculated as $100 \mathrm{D} /(\mathrm{D}+8 \mathrm{C})$, i.e. the along-transect linear travel track length as a percent of the

182 total on-transect track length; taking the length of a crossing movement as $8.0 \mathrm{~m}$ (the rounded

183 average value of SL width). Third, the total on-transect track extent (D+8C; m of track $/ \mathrm{km}$

184 surveyed) was employed as an indicator of the relative usage of forest or SL habitats, with larger

185 values reflecting the combined effects of higher abundance, preferential use, and travel speed.

186 Habitat usage intensity was also calculated for individual $100 \mathrm{~m}$ sub-transects within the forest

187 transects.

Part way through the study, the trees in portions of three sites were harvested, reducing the transect length for six forest and two SL surveys to $800 \mathrm{~m}$ and another four SL surveys to $600 \mathrm{~m}$. Data were simulated for missing sub-transects in post-harvest years using integer averages of taxon-specific tracks recorded on these sub-transects pre-harvest; the simulated data comprised about $1 \%$ of all analysed tracks.

\section{Snow depth and support}

At each survey, snow depth (SD) and snow penetration (SP) were recorded at the beginning and end of each sub-transect (11 repeats per transect). SP was measured at the crosswise position on the transect where snow was judged to be most supportive by dropping a $20 \mathrm{~g}$ weight from a height of $1.0 \mathrm{~m}$ and recording its final depth. SD and SP measurements (in meters) were then averaged for each transect, and a snow support index was calculated as $100(\mathrm{SD}-\mathrm{SP}) / \mathrm{SD}$, i.e., the percent of snow depth that was resistant to the dropped weight; higher values indicate better support for surface-active animals. 
201

202

203

204

205

206

207

208

209

210

211

212

213

214

215

216

217

218

219

220

221

222

223

\section{Statistical analyses}

The study design uses sites as the unit of replication in statistical analyses, and the habitat type (e.g., SL or forest) as the predictor variable; the analysed response variables are the sitescale measurements of mammal tracks (with each taxon or body size-diet group separately analysed as an independent response variable) and snow condition. Preliminary comparisons of track distance ( $\mathrm{m} / \mathrm{km}$ surveyed) across the three sampling winters using repeated measures ANOVA, with sites as subjects and year-site combinations as replicates ( $3 \mathrm{X} 14)$ showed no significant effect of sampling year $(P>0.05)$ for nine of 13 separately-tested taxa, with only four being significant: gray wolf $(P=0.004)$, red squirrel $(P<0.001)$, mouse $(P=0.005)$ and shrew $(P<0.001)$. For efficiency in subsequent analyses, irrespective of taxon, we used the average measurements across the nine repeat surveys at each transect for all taxa, consistent with our focus on spatial rather than temporal processes. For large-bodied species, there could be some occasions where large home ranges enabled particular individuals to contribute in part to measurements at more than one site, but an individual's behaviour at a given site is here viewed as an independent response to the environment at that time and place, and the measurements used in analyses were based on all relevant tracks within a taxon or body size-diet group irrespective of individual mammals (being site-scale averages of all the outcomes of all individual's independent decisions across nine repeat visits during three years). and habitat usage intensity were tested using paired t-tests $(n=14$ transect pairs; Currell \& Dowman 2009) for all individual taxa and body size-diet groups, for which at least 100 tracks had been recorded from at least 10 sites. In cases where data did not meet the normality assumption tests were also calculated using Wilcoxon signed rank tests for paired samples. 
224 Where the homoscedasticity assumption was violated, values were transformed, which also

225 addressed outliers (Supplementary Tables 1, 2, 3). Mean difference confidence intervals (95\%)

226 and Cohen's effect sizes were calculated (Lakens 2013) and power to detect mean differences of

22720,50 and $80 \%(\alpha=0.05)$ using $t$-tests with observed sample variances (Thomas 1997, but see

228 Hoenig \& Heisey) was assessed using G*Power (Faul 1992). Snow depth and support were

229 compared using $t$-tests and we used linear regression to test the relationships between linear

230 travel propensity and snow support on SL transects ( $\mathrm{n}=14$ sites).

231 To test the effect of proximity to SL edges on habitat usage intensity within forest transects,

232 sub-transect (each $0.1 \mathrm{~km}$ ) values for each mammal, were compared using repeated measures

233 ANOVA, with sites as subjects. Repeated measures is a design where subjects are measured

234 repeatedly (Quinn \& Keough 2002). Here sites were measured repeatedly by sampling sub-

235 transects (10 per site) which were located at varying distances form the nearest SL. Sub-transects

236 were grouped into three distance categories based on this distance: 0-50 m ( $\mathrm{n}=36$ sub-transects),

$23751-150 \mathrm{~m}(\mathrm{n}=44), 151-570 \mathrm{~m}(\mathrm{n}=60)$. The maximum distance of $570 \mathrm{~m}$ and the unequal sample

238 sizes occurred because of SLs that crossed eight forest transects, or when the "far" end of some

239 forest transects was near a SL. Repeated measures ANOVA assumes normality of residuals and

240 equal variances. Sub-transect measures were log-transformed prior to analysis and where

241 Mauchly's test for sphericity (equal variances) was violated, the Greenhouse-Geisser correction

242 was used. Residuals were assessed visually using box-plots and the Shapiro-Wilk test. Effect size

243 was calculated as partial and generalized eta squared (Lakens 2013). Analyses were conducted

244 using excel and R (R Core Team 2014; ez and stats packages). The potential for false discovery

245 by multiple t-tests and ANOVAs was assessed using the Benjamini-Hochberg procedure (Pike

246 2011) with a false discovery rate of 0.15 . 


\section{RESULTS}

248 The 17 identified taxa (Table 1) accounted for $99 \%$ of the recorded tracks, and comprised five

249 large predator species, five mid-sized predator taxa, two large herbivore taxa, two mid-sized

250 herbivore species and three small mammal taxa. The most common taxa in each body size-diet

251 group were, respectively, coyotes, marten, deer, squirrels and voles, and 13 taxa were

252 sufficiently common to be individually analysed (Table 1). Across all 17 taxa, approaches

253 comprised $8 \%$ of all identified tracks. Most (89\%) of the remainder (i.e., on-transect tracks) were

254 crossings, the others being linear travels. However crossings contributed less of the recorded on-

255 transect track length (76\%) because of the greater individual lengths of linear travel movements.

256 The results presented below have been condensed but additional details, results of power analysis

257 and Benjamini-Hochberg procedure are provided in Supplementary Tables 1-11.

\section{Mammal movements and habitat use in seismic line clearings versus forest}

259 One of the 13 individually-analysed taxa (hare), and two of the five body size-diet groups (mid-

260 sized predators and large and mid-sized herbivores), crossed SL transects slightly but

261 significantly less often than was the case for continuous forest transects (Figures 2a, 3a).

262 However, even in these three cases, the reduction in crossing propensity was small as the average

263 percent of approaches to SLs that resulted in crossings was $89 \%$, compared with $92 \%$ in forest

264 (Figures 2a, 3a, Supplementary Table 1) and for taxa and body-size diet groups, the mean

265 difference detected was $13 \%$ or less $(|0.4|$ to $|13| \%$, Supplementary Table 1). Small mammals

266 (mouse, shrew) trended toward lower crossing rates in forest compared to seismic lines, although

267 mean differences were not consistently positive or negative across sites which led to confidence

268 intervals which ranged from positive to negative (Supplementary Table 1) 
269 \# insert Figure 2 and 3 approximately here\#

SLs had substantial impacts on linear travel movements and habitat use, which varied among taxa and body size-diet groups. Five taxa and three body size-diet groups significantly

272 favored SLs for linear travel, compared with forest transects (Figures 2b, 3b). Across all

273 mammals, linear travels averaged $42 \%$ and $6 \%$ of the distances moved within SL and forest transects respectively (Figure 3b, Supplementary Table 2), even though the total habitat usage intensity (movement in any direction) was similar in SLs and forest (Figure 3c, Supplementary 276 Table 3). respectively (Figure 3b, Supplementary Table 2); three of four analysed component species also showed significant differences (Figure 2b). Second, the overall habitat usage intensity by large predators, both collectively and individually, was much greater in SLs than in forest (Figures 2c, (averaging 54\% and 14\% of movement distances in SLs and forest respectively), together with a statistically significant difference in both component taxa (Figures $2 b, 3 b$ ). However their habitat usage intensity in SLs was collectively similar to that in forest (Figure 3c), and was significantly greater only for the rarer of the two component taxa (moose/elk; Figure 2c). purpose (averaging 15\% and 3\% of their distances moved in SLs and forest respectively, Supplementary Table 2). However both mid-sized predators and herbivores had significantly greater usage intensity in forest than in SL clearings (Figure 3c), indicating a forest preference 
291 for other activities. Component taxa within these groups showed no consistent patterns, apart

292 from strong avoidance of SL clearings by marten (Figure 2c, Supplementary Table 3). Among

293 small mammals, linear travel movements were uncommon, and there was little difference

294 between SL and forest in either linear travel or usage intensity (Figures 2b,c, 3b,c).

295 Snow depth and support

296

297

298

299

300

301

302

303

304

305

306

307

308

309

310

311

Snow was deeper on SLs than in forest (respective mean depths $0.22 \mathrm{~m}$ and $0.17 \mathrm{~m}$; SEs

0.02, 0.01; paired t-test $P=0.002, \mathrm{n}=14$ transect pairs), and also more supportive (mean index values $69 \%$ and $54 \%$; SEs $1.7,2.0 ; P<0.001)$. Correlations between linear travel propensity and snow support were significantly positive for large herbivores collectively and for deer (respectively, $\mathrm{r}^{2}=0.33,0.41, P=0.03,0.01 ; \mathrm{n}=14 \mathrm{SL}$ transects), but not for other taxa or body size-diet groups (all $\left.\mathrm{r}^{2}<0.22, P>0.05\right)$.

\section{Edge effects on mammal activity in forest adjoining seismic line clearings}

Most mammals within forest adjoining SL clearings showed no edge-sensitivity. The on-transect usage intensity was greatest for sub-transects closer to SLs among only the moose/elk taxon which significantly selected for locations nearer to SLs (Figure 4, Supplementary Table 4). In contrast, shrew tended to weakly avoid forest sub-transects closest to SL clearings (Figure 4).

ANOVAs for the remaining 11 taxa and five body size-diet groups all gave $P$ values $>0.10$, graphical data visualisations showed no strong trends and effect sizes were generally low $\left(\eta_{p}{ }^{2}<0.20\right)$ for all but moose/elk $\left(\eta_{p}{ }^{2}=0.451\right.$, Supplementary Table 4$)$.

\# Figure 4 approximately here \#

\section{DISCUSSION}


312 Effects of linear forest clearings on functional habitat fragmentation

313 Mammal crossing rates of SL clearings were not substantially different from crossing rates on

314 forested control transects for most taxa recorded in this study area. Even the taxon for which SLs

315 had a significant negative effect on crossing propensity, the magnitude of decrease was

316 quantitatively minor (9\%) and two small mammals (mouse and shrew) trended toward higher

317 rates of seismic line crossing compared to forest. These results suggest that SLs were not strong

318 barriers to movement, a finding contrary to the widely expected idea that linear forest clearings

319 substantially increase habitat fragmentation by impeding movements, especially for smaller

320 mammals, which have limited mobility and smaller home ranges (Peter et al. 2013). Indeed,

321 previous studies in temperate (Oxley et al. 1974; Rico et al. 2007) and tropical forests (Goosem

322 2002) found that unsealed roads with widths similar to the SLs in our study region impeded

323 small mammal crossing movements, although this may have been at least in part a response to

324 motor vehicles and road surface features. However other types of non-road linear clearing such

325 as powerline corridors in tropical forest (Goosem 1997) and ski pistes in temperate forest (Negro

326 et al. 2013) have also impeded small mammal movements.

In general, small mammals are impeded more by wider openings than narrow openings

and more by linear clearings covered in materials which differ from the surrounding forest (e.g.

asphalt, Peter et al. 2013). The clearing widths shown to have an inhibitory influence on small

mammal crossings elsewhere were $60 \mathrm{~m}$ (powerline corridor; Goosem 1997) and 83 m (ski

331 pistes; Negro et al. 2013). In contrast, this study’s SLs were much narrower (8 m). Furthermore,

332 both the SLs and forest in our boreal study were covered in snow to a depth of about $20 \mathrm{~cm}$.

333 Therefore, our study's finding of little impedance of small mammal crossings by non-road linear

334 clearings may be due to their relatively narrow width together with their winter surface 
335 resemblance to the surrounding forest. Our results apply only to surface movements. Small

336 mammals and their predators (e.g. weasel, marten) move in the subnivean space during the snow

337 cover period, and the more compacted snow in the SL clearings could potentially impact such

338 movements. Further research is needed to test this possibility.

It is also possible that the study region's SL clearings may constitute a greater movement

barrier during summer, when the ground surface structure and composition contrast more

strongly with surrounding forest. In evergreen Australian woodlands, movements of small

mammals were unaffected by very narrow SLs (1.4 and $4.2 \mathrm{~m})$, but some were impeded by wider

fire access clearings (6-7 m) which had been surfaced with gravel (Carthew et al. 2013). To

understand the relative importance of clearing width and surface material (and their interaction)

requires further comparative research in other regions and seasons; a significant information gap

since linear seismic clearings occur extensively throughout forested areas overlying oil and gas

It remains possible that some mammals' movements may have been restricted at rates which were too small in magnitude to be detected by this study. Although the current study required a large sampling effort, detection of very small differences would require additional sampling.

352 Effect sizes have been provided (Supplementary Table 1) to support future research planning,

354 in any such future research.

SL clearings also had very little spatial edge effect on mammal habitat use in adjacent forest

356 (at least in winter, and up to $570 \mathrm{~m}$ distant; Figure 4), across diverse taxa and body size-diet 
357 groups. Other studies have concluded that altered physical conditions within forest adjacent to

358 clearings can lead to increased abundances of shrubs and saplings (Harper et al. 2005), and these

359 may in turn attract some mammals to the forest edges (Lidicker 1999), which may explain this

360 study's observed increase in habitat usage intensity by moose/elk within $50 \mathrm{~m}$ of SLs. On the

361 other hand, some species could be expected to avoid these same areas, as either a direct response

362 to the edge conditions or an indirect response to the presence of humans or predators (Dyer et al.

363 2001). However, we found only one near-significant negative trend for shrews. This result may

364 have been produced due to unequal sample sizes between sites (subjects) which reduced

365 statistical power or if SLs had a strong negative effect on mammal habitat use at all distances up

$366570 \mathrm{~m}$ from their edges. However, we saw very little difference in habitat useage intensity as

367 distance from SLs increased.

In contrast, Dyer et al. (2001) reported that a large herbivore (caribou) avoided forest within $100 \mathrm{~m}$ of SLs, interpreted as a learned response to higher abundances of predators such as gray wolves. Caribou are known to avoid predators by spatially segregating from them (FestaBianchet et al. 2011). This raises the question of why there was no such avoidance by the large herbivores in our study, but rather an increase in habitat usage near SL edges in the case of

373 moose/elk. Differing species-specific prey escape modes (Wirsing et al. 2010) are a likely contributing factor. Among our study's large herbivores, elk escape predation by fleeing and moose use active defence. Deer use a combination of fleeing, active defence and early detection. Use of these alternative strategies to predator avoidance could enable this study's large

377 herbivores to persist in seeking opportunities for travel and resource access associated with nonroad linear clearings, albeit with potentially greater risk of encountering predators (McKenzie et al. 2012). Elsewhere, despite avoiding forest within $50 \mathrm{~m}$ of linear clearings when resting, elk 
380 were more likely to engage in long distance movements in areas with high predation risk in close

381 proximity to linear clearings (Frair et al. 2005).

382 Human use deterred wolves and elk from using forest habitat within $50 \mathrm{~m}$ of recreational

383 trails in another boreal forest region (Rogala et al. 2011). However human foot tracks on our

384 study SLs averaged only $39 \mathrm{~m} / \mathrm{km}$ and were restricted to six of 14 sites over all three winters,

385 providing very little opportunity for edge-avoidance responses to humans.

\section{Other influences of linear clearings on mammal activities and communities}

387 It has long been suggested that mammals may frequently use non-road linear forest clearings for

388

389

390

391

392

393

394

395

396

397

398

399

400

401

movement (Forman 1995a), but supporting empirical evidence has been lacking for many

species. Individual-based studies of movement paths using telemetry and back-tracking data have shown that large predators such as gray wolf and coyote move preferentially along forest trails (Whittington et al. 2005; Latham et al. 2011; Gese et al. 2013). In the present study, a different method (site-based measurements of snow track data) yielded a similar finding for both of these species, as well as for cougar, the combined moose/elk taxon, deer and collectively for large and medium-sized predators and large herbivores.

Snow supportiveness (compaction) was greater in this study's SLs than in surrounding forest, and across sites the positive correlations between SL snow supportiveness and linear travel propensity for deer and large herbivores suggests that this increased support may have contributed to the appeal of SLs as travel routes. However travel movements of large predators collectively were uninfluenced by snow supportiveness. Gese et al. (2013) concluded that coyotes selected forest trails for their more compacted snow conditions. However the snow depth in that study $(0.78 \mathrm{~m})$ had greater potential to impede large carnivores' movements than was the 
402 case for the $0.17 \mathrm{~m}$ deep snow in the present study's forest transects. Our SLs were also likely

403 favored for linear movements because of their more open terrain. Therefore these results may

404 also extend to snow-free seasons and areas, as reported for black bears in boreal forest (Tigner et

405 al. 2014) and cougars in tropical forest (Harmsen et al. 2010).

Among the five body size-diet groups, the observed relative proportions of linear travel movement on SLs in the present study agree with the order expected on the basis of energetic travel efficiency (large predators $>$ large herbivores $>$ mid-sized predators $>$ mid-sized herbivores > small mammals; see Introduction). Furthermore, since body size and diet correlate with metabolic requirements independently of habitat, this pattern of differential benefit, and consequent differences in the amount of SL use for linear travel, could also be expected to occur in non-road linear clearings within other regions and other types of dense vegetation.

414 (reflecting the combined outcome of changes in movement and resource use), when considered collectively, provide information about the community-level impacts of these linear clearings. Overall, the winter mammal assemblage within the forest was dominated by medium-sized 417 herbivores (hare, squirrel), with deer (a large herbivore) also common. In contrast, there was a compositional shift within the SL clearings, so that the mammal assemblage was more evenly

419 dominated by large predators (especially coyote), medium herbivores and deer (Figures 2c, 3c, compare light to dark bars): a change in both species and trophic composition in favor of large

421 predators, and away from medium herbivores. Medium-sized mammals in general (both

422 herbivores and predators) showed a depressed usage intensity in the SL clearings. This may be 423 an avoidance response to the high activity of larger predators in these SLs; single-species 
424 research into activity and habitat use by hares (Hodson et al. 2010) and marten (Moriarty et al.

425 2015) in boreal forest reported lower activity in clearings, associated with reduced predation risk. McKenzie et al. (2012) predicted higher encounter rates between predators and prey in

427 forests with high densities of non-road linear clearings, and thus greater predator efficiency.

428 However, since increased abundance or activity of the large predators may induce various spatial 429 avoidance or other escape responses among different species of prey (which could themselves 430 belong to different trophic levels), the potential community-wide effects of SL-induced predator 431 concentrations are complex. If spatial avoidance occurs, then the prey may suffer from reduced 432 resource access, whereas if other escape mechanisms are used they would be more likely to be 433 more heavily predated; in either case there are likely to be impacts on subsequent survival and 434 reproduction, and ultimate consequences for population dynamics and density. More generally, 435 the large potential for heterogeneous responses to linear infrastructure by different species 436 (Benitez-Lopez et al. 2010) highlights a need for further comparisons of species-specific 437 responses to this and other forms of habitat fragmentation (Gehring \& Swihart 2003).

\section{Management implications}

439 Habitat loss and fragmentation present a well-recognized conservation risk for ground-active mammals (Forman 1995a), and may be particularly perilous for mammalian carnivores which have experienced large population and range contractions over the past two centuries (Ripple et al. 2014). However our results indicate that non-road linear clearings in boreal forest did not reduce most species' potential movements but instead increased them, especially for large

444 predators and herbivores. Hence, a management focus on simply facilitating crosswise 445 movement in boreal forests containing SLs would be of doubtful value. 
447 become widespread globally, and have cascading ecosystem consequences that include elevated

448 densities of large herbivores and consequent suppression of vegetation (Ripple \& Beschta 2012).

449 However the boreal forests of the Canadian Rocky Mountains still support a relatively intact and

450 diverse mammal assemblage which includes several species of large carnivore. In the study

451 region, SLs directly occupied $1 \%$ of otherwise forested land, while a further $17 \%$ of forest was

452 located within $50 \mathrm{~m}$ of SL edges (Pattison et al. 2016). This study found that the direct effects of

453 SLs on mammal movements were mostly confined to the relatively small areas of actual linear

454 clearing. However, within these clearings there were large non-barrier impacts on movement and

455 habitat use, with arguably greatest advantage to top predators, associated with an altered trophic

456 structure of the mammal community. When a region is criss-crossed by extensive linear clearing

457 networks, potential population increases in large predators could lead to increased impacts on

458 other species. These consequences may be judged as either desirable or undesirable from a

459 conservation management perspective: for example the benefit to a threatened large carnivore

460 species could be desirable, but such a change in a common predator would be undesirable for a

461 threatened prey species. Understanding the likely outcomes for common herbivores or for

462 vegetation requires further research. Furthermore, these networks of narrow clearings also

463 facilitate human access for activities such as hunting or recreation, with potentially detrimental

464 impacts whose mitigation would require active management. Since this was an observational

465 study we could not draw conclusions with respect to causal relationships due to confounding

466 variables which can only be controlled through randomized experimental designs. We have

467 suggested explanations for our findings but further research is needed to understand the complex

468 effects seismic lines and other linear clearings have on animal communities. 


\section{REFERENCES}

470 Archibald, J. H., G. D. Klappstein, and I. G. W. Corns. 1996. Field guide to ecosites of

471 southwestern Alberta. Canadian Forest Service, Edmonton, AB.

472 ASRD. 2000. The general status of Alberta wild species. Alberta Sustainable Resource

473 Development, Edmonton, AB.

474 Benitez-Lopez, A., R. Alkemade, and P. A. Verweij. 2010. The impacts of roads and other

475 infrastructure on mammal and bird populations: a meta-analysis. Biological Conservation

$476 \quad 143: 1307-1316$.

477 Butt, N., H. L. Beyer, J. R. Bennett, D. Biggs, R. Maggini, M. Mills, A. R. Renwick, L. M.

478 Seabrook, and H. P. Possingham. 2013. Biodiversity risks from fossil fuel extraction. Science

$479 \quad 342: 425-426$.

480 Carthew, S. M., K. M. W. Jones, and M. Lawes. 2013. Responses of small vertebrates to linear

481 clearings in a south Australian woodland. Ecological Research 28:1003-1010.

482 Coffin, A. W. 2007. From roadkill to road ecology: a review of the ecological effects of roads.

483 Journal of Transport Geography 15:396-406.

484 Currell, G., and A. Dowman 2009. Essential mathematics and statistics for science. John Wiley 485 \& Sons, West Sussex, UK.

486 Dyer, S. J., J. P. O'Neill, S. Wasel, and S. Boutin. 2001. Avoidance of industrial development by 487 woodland caribou. Journal of Wildlife Management 65:531-542.

488 Environment Canada. 2009. Canadian climate normals 1971-2000. National climate data and 489 information archive. Environment Canada, Ottawa. 
490 Faul, F., E. Erdfelder. 1992. GPower: Apriori-, post hoc-, and compromise power analyses

491 [computer program v.3.1.9.2]. Bonn University, Bonn, Germany

492 Festa-Bianchet, M., J. C. Ray, S. Boutin, S. D. Cote, and A. Gunn. 2011. Conservation of 493 caribou (Rangifer tarandus) in Canada: an uncertain future. Canadian Journal of Zoology 89:419494434.

495 Forman, R. T. T. 1995. Corridor attributes, roads, and powerlines. In: Land mosaics: the ecology 496 of landscapes and regions. Cambridge University Press, Cambridge, 145-176.

497 Forman, R. T. T. 1995b. Species movement in mosaics. In: Land mosaics: the ecology of 498 landscapes and regions. Cambridge University Press, Cambridge, 364-402.

499 Forrest, L. R. 1988. Field guide to tracking animals in snow. Stackpole Books, Mechanicsburg, 500 PA.

501 Frair, J. L., E. H. Merril, D. R. Visscher, D. Fortin, H. L. Beyer, and J. M. Morales. 2005. Scales

502 of movement by elk (Cervus elaphus) in response to heterogeneity in forage resources and 503 predation risk. Landscape Ecology 20:273-287.

504 Garland, T. 1983. Scaling the ecological cost of transport to body mass in terrestrial mammals. 505 The American Naturalist 121:571-587.

506 Gehring, T. M., and R. K. Swihart. 2013. Body size, niche breadth, and ecologically scaled 507 responses to habitat fragmentation: mammalian predators in an agricultural landscape. Biological 508 Conservation 109:283-295.

509 Gese, E. M., J. L. B. Dowd, and L. M. Aubry. 2013. The influence of snowmobile trails on 510 coyote movements during winter in high-elevation landscapes. PLOS One 8:1-10. 
511 Gittleman, J. L. 1985. Carnivore body size: ecological and taxonomic correlates. Oecologia $512 \quad 67: 540-554$.

513 Goosem, M. 1997. Internal fragmentation: the effects of roads, highways, and powerline 514 clearings on movements and mortality of rainforest vertebrates. In: Laurance, W.F. and R. O.

515 Bierregaard, ed. Tropical forest remnants: ecology, management, and conservation of fragmented 516 communities. Chicago: University of Chicago Press, 241-255.

517 Goosem, M. 2002. Effects of tropical rainforest roads on small mammals: fragmentation, edge 518 effects and traffic disturbance. Wildlife Research 29:277-279.

519 Haddad, N. M., D. R. Browne, A. Cunningham, B. J. Danielson, D. J. Levey, S. Sargent, and T. 520 Spira. 2003. Corridor use by diverse taxa. Ecology 84:609-615.

521 Harestad, A. S., and F. L. Bunnel. 1979. Home range and body weight a reevaluation. Ecology $52260: 389-402$.

523 Harmsen, B. J., R. J. Foster, S. Silver, L. Ostro, and C. P. Doncaster. 2010. Differential use of 524 trails by forest mammals and the implications for camera-trap studies: a case study from Belize. 525 Biotropica 42:126-133.

526 Harper, K. A., E. MacDonald, P. J. Burton, J. Chen, K. D. Brosofske, S. C. Saunders, E. S. 527 Euskirchen, D. Roberts, M. S. Jaiteh, and P.-A. Essen. 2005. Edge influence on forest structure 528 and composition in fragmented landscapes. Conservation Biology 19:768-782.

529 Hodson, J., D. Fortin, and L. Belanger. 2010. Fine-scale disturbances shape space-use patterns of 530 a boreal forest herbivore. Journal of Mammalogy 91:607-619.

531 Hoenig, J.M. D.M. Heisey. The abuse of power. The American Statistician 55:19-24. 
532 Kolowski, J. M., and A. Alonso. 2012. Primate abundance in an unhunted region of the northern

533 Peruvian Amazon and the influence of seismic oil exploration. International Journal of

534 Primatology 33:958-971.

535 Lakens, D. 2013. Calculating and reporting effect sizes to facilitate cumulative science: a

536 practical primer for $t$-tests and ANOVAs. Frontiers in Psychology 4:1-12.

537 Latham, A. D. M., M. C. Latham, M. S. Boyce, and S. Boutin. 2011. Movement responses by

538 wolves to industrial linear features and their effect on woodland caribou in northeastern Alberta.

539 Ecological Applications 21:2854-2865.

540 Lidicker, W. Z. 1999. Responses of mammals to habitat edges: an overview. Landscape Ecology $541 \quad 14: 333-343$.

542 McGregor, R. L., D. J. Bender, and L. Fahrig. 2008. Do small mammals avoid roads because of 543 the traffic? Journal of Applied Ecology 45:117-123.

544 McKenzie, H. W., E. H. Merrill, R. J. Spiteri, and M. A. Lewis. 2012. How linear features alter 545 predator movement and the functional response. Interface Focus 2:205-216.

546 Morelli, F., M. Beim, L. Jerzak, D. Jones, and P. Tryjanowski. 2014. Can roads, railways and 547 related structures have positive effects on birds? a review. Transportation Research 30:21-31.

548 Moriarty, K. M., C. W. Epps, M. G. Betts, D. J. Hance, J. D. Bailey, and W. J. Zielinski. 2015.

549 Experimental evidence that simplified forest structure interacts with snow cover to influence 550 functional connectivity for Pacific martens. Landscape Ecology 30:1865-1877.

551 Negro, M., C. Novara, S. Bertolino, and A. Rolando. 2013. Ski-pistes are ecological barriers to 552 forest small mammals. European Journal of Wildlife Management 59:57-67. 
553 Oxley, D. J., M. B. Fenton, and G. R. Carmody. 1974. The effects of roads on populations of

554 small mammals. Journal of Applied Ecology 11:51-59.

555 Pattison, C. A., M. S. Quinn, P. Dale, and C. P. Catterall. 2016. The landscape impact of linear 556 seismic clearings for oil and gas development in boreal forest. Northwest Science 90:340-354.

557 Peter, F. P., G. M. Vacas, J. Rodriguez, and C. Grilo. 2013. Effects of roads on spatial behaviour 558 and abundance of small mammals: gaps in knowledge. Oecologia Australis 17:63-76.

559 Pike, N. 2011. Using false discovery rates for multiple comparisons in ecology and evolution.

560 Methods in Ecology and Evolution 2:278-282.

561 Potapov, E., A. Bedford, F. Bryntesson, S. Cooper, B. Brown, and D. Robertson. 2011. Impact of

562 snow cover on movements and habitat choice by suburban white-tailed deer (Odocileus

563 virginianus). Bulletins of the New Jersey Academy of Science 56:5-8.

564 Quinn, G.P., M.J. Keough 2002. Experimental Design and Data Analysis for Biologists.

565 Cambridge University Press, Cambridge, UK.

566 R Core Team. 2014. R: A language and environment for statistical computing. R Foundation for

567 Statistical Computing, Vienna, Austria.

568 Rabanal, L. I., H. S. Kuehl, R. Mundry, M. M. Robbins, and C. Boesch. 2010. Oil prospecting

569 and its impacts on large rainforest mammals in Loango National Park, Gabon. Biological

570 Conservation 143:1017-1024.

571 Rico, A., P. Kindlmann, and S. Frantisek. 2007. Barrier effect of roads on movements of small

572 mammals. Folia Zoologica 56:1-12. 
573 Ripple, W. J., and R. L. Beschta. 2012. Trophic cascades in Yellowstone: the first 15 years after

574 wolf reintroduction. Biological Conservation 145:205-213.

575 Ripple, W. J., J. A. Estes, R. L. Beschta, C. C. Wilmers, E. G. Ritchie, M. Hebblewhite, J.

576 Berger, B. Elmhagen, M. Letnic, M. P. Nelson, O. J. Schmitz, D. W. Smith, A. D. Wallach, and

577 A. J. Wirsing. 2014. Status and ecological effects of the world's largest carnivores. Science

$578 \quad 343: 11$.

579 Rogala, J. K., M. Hebblewhite, J. Whittington, C. A. White, J. Coleshill, and M. Musiani. 2011.

580 Human activity differentially redistributes large mammals in the Canadian Rockies national

581 parks. Ecology and Society 16:24.

582 Smith, T. M., and R. L. Smith 2009. Elements of ecology. Benjamin Cummings, Toronto.

583 Swihart, R. K., N. A. Slade, and B. J. Bergstrom. 1988. Relating body size to the rate of home

584 range use in mammals. Ecology 69:393-399.

585 Telfer, E. S., and J. P. Kelsall. 1984. Adaptation of some large North American mammals for

586 survival in snow. Ecology 65:1828-1834.

587 Thomas, L. 1997. Retrospective power analysis. Conservation Biology 11:276-280.

588 Tigner, J., E. M. Bayne, and S. Boutin. 2014. Black bear use of seismic lines in northern Canada.

589 Journal of Wildlife Management 78:282-292.

590 Trombulak, S. C., and C. A. Frissell. 2000. Review of ecological effects of roads on terrestrial

591 and aquatic communities. Conservation Biology 14:18-30.

592 Whittington, J., C. C. St. Clair, and G. Mercer. 2005. Spatial responses of wolves to roads and

593 trails in mountain valleys. Ecological Applications 15:543-553. 
594 Wirsing, A., K. E. Cameron, and M. R. Heithaus. 2010. Spatial responses to predators vary with 595 prey escape mode. Animal Behaviour 79:531-537. 
596 Figure 1: Example of a study site layout: (a) shows a typical landscape context and the paired 597 seismic line (SL) and forest transects; (b) diagrams the transect details, including their division 598 into 10, $0.1 \mathrm{~km}$ sub-transects and the three types of individual movement (approaches, crossings 599 or travels).

600 Figure 2: Comparison of mammal movement and habitat use between seismic line (SL) 601 clearings and forest habitat for different species. (a) Crossing propensity (\% of transect 602 approaches which fully crossed), (b) Linear travel propensity (\% of track length which was linear 603 along the transect), (c) Habitat usage intensity (total on transect track extent). Species are ordered 604 by body size-diet group (see Table 1 for abbreviations): large predator (L pred), mid-sized 605 predator (M pred), large herbivore (L herb), mid-sized herbivore (M herb), small mammal (S 606 mam). Values are means and standard errors $(n=14$ paired transects per habitat), with results 607 declared significant by Benjamini-Hochberg $(\mathrm{BH})$ procedure and paired t-test $P$-values 608 (unadjusted, $* P<0.05, * * P<0.01, * * * P<0.001$ ). Results declared non-significant by BH 609 procedure and unadjusted $P<0.1$ indicated by + (Supplementary Tables $8,9,10)$.

610 Figure 3: Comparison of mammal movement and habitat use between seismic line (SL)

611 clearings and forest transects for different body size-diet groups: large predator (L pred), mid612 sized predator (M pred), large herbivore (L herb), mid-sized herbivore (M herb), small mammal 613 (S mam). (a) Crossing propensity (\% of transect approaches which fully crossed), (b) Linear 614 travel propensity (\% of track length which was linear along the transect), (c) Habitat usage 615 intensity (total on transect track extent for multiple species recorded simultaneously). Values are 616 means and standard errors ( $\mathrm{n}=14$ paired transects in forest and SLs), with results declared 617 significant by Benjamini-Hochberg $(\mathrm{BH})$ procedure and paired t-test $P$-values (unadjusted, $* P<$ 
$\left.6180.05,{ }^{* *} P<0.01,{ }^{* * *} P<0.001\right)$. Results declared non-significant by BH procedure and 619 unadjusted $P<0.1$ indicated by $+($ Supplementary Tables $8,9,10)$.

620 Figure 4: Mean moose (a) and shrew (b) habitat usage intensity (meters of track per sub-

621 transect, standard error) within $100 \mathrm{~m}$ sub-transects which were located in forest, at various

622 distances from the nearest seismic line. Results of repeated measures ANOVA where forest sub623 transects within sites (subjects, $\mathrm{N}=14$ ) were measured repeatedly (10 sub-transects per site) and 624 classified by distance to the nearest seismic line ( $0-50 \mathrm{~m}$ ( $\mathrm{n}=36$ sub-transets); $51-150 \mathrm{~m} \quad(\mathrm{n}=44)$;

$625151-570 \mathrm{~m}(\mathrm{n}=60))$, to assess the effect of distance to SL on habitat usage intensity $\left({ }^{*} P<0.05\right)$.

626 Refer to Supplementary Table 4 for results for all mammals analyzed.

627

628 


\section{Table $\mathbf{1}$ (on next page)}

Mammals identified in study

Mammals identified in the study, their functional groups based on diet and size, and relative occurrence (numbers of sites out of 14 , and track characteristics). 
Table 1: Mammals identified in the study, their functional groups based on diet and size, and relative occurrence (numbers of sites out of 14 , and track characteristics).

\begin{tabular}{|c|c|c|c|c|c|c|c|}
\hline Taxon $^{\mathrm{a}}$ & $\mathrm{Abr}^{\mathrm{a}}$ & Species $^{\mathrm{a}}$ & $\begin{array}{l}\text { Weight } \\
(\mathrm{kg})^{\mathrm{b}}\end{array}$ & Functional group ${ }^{\mathrm{b}}$ & $\begin{array}{l}\text { No. } \\
\text { sites }\end{array}$ & $\begin{array}{r}\text { Total } \\
\text { tracks }^{\mathrm{c}}\end{array}$ & $\begin{array}{r}\text { Movement } \\
\text { dist. }(\mathrm{m} / \mathrm{km})^{\mathrm{d}} \\
\end{array}$ \\
\hline Grizzly bear & $\mathrm{gb}^{*}$ & Ursus arctos & 204 & Large predator & 1 & 1 & 2.7 \\
\hline Cougar & $\mathrm{cu}$ & Puma concolor & 67 & Large predator & 13 & 102 & 14.6 \\
\hline Gray wolf & gw & Canis lupus & 37 & Large predator & 10 & 126 & 41.1 \\
\hline Coyote & cy & Canis latrans & 16 & Large predator & 14 & 414 & 137.7 \\
\hline Lynx & ly & Lynx canadensis & 12 & Large predator & 13 & 120 & 7.7 \\
\hline Bobcat & $\mathrm{bc}^{*}$ & Lynx rufus & 9.1 & Mid-sized predator & 3 & 4 & 0.1 \\
\hline Fisher & $\mathrm{fi}^{*}$ & Pekania pennanti & 3.5 & Mid-sized predator & 7 & 15 & 0.7 \\
\hline Red fox & $\mathrm{rf}^{*}$ & Vulpes vulpes & 5.5 & Mid-sized predator & 9 & 19 & 1.0 \\
\hline Marten & $\mathrm{ma}$ & Martes americana & 1.0 & Mid-sized predator & 13 & 1,829 & 55.9 \\
\hline Weasel & we & $\begin{array}{l}\text { Mustela erminea, } M \text {. frenata, } M \text {. } \\
\text { nivalis }\end{array}$ & 0.13 & Mid-sized predator & 14 & 383 & 12.8 \\
\hline Moose /elk & mo/ek & Alces alces, Cervus elaphus & 355 & Large herbivore & 14 & 627 & 27.8 \\
\hline Deer & de & $\begin{array}{l}\text { Odocoileus hemionus, } O . \\
\text { virginianus }\end{array}$ & 94 & Large herbivore & 14 & 6,949 & 304.1 \\
\hline Hare & ha & Lepus americanus & 1.5 & Mid-sized herbivore & 14 & 8,191 & 248.1 \\
\hline Red squirrel & rs & Tamiasciurus hudsonicus & 0.25 & Mid-sized herbivore & 14 & 14,309 & 437.6 \\
\hline Vole & vo & $\begin{array}{l}\text { Clethrionomys gapperi, } \\
\text { Phenacomys intermedius, Microtus } \\
\text { longicaudus, } M \text {. pennsylvanicus }\end{array}$ & 0.020 & Small mammal & 14 & 1,737 & 40.2 \\
\hline Mouse & $\mathrm{mu}$ & Peromyscus maniculatus & 0.016 & Small mammal & 14 & 1,015 & 27.5 \\
\hline Shrew & sh & $\begin{array}{l}\text { Sorex arcticus, } S \text {. cinereus, } S . \text { hoyi, } \\
\text { S. monticolus }\end{array}$ & 0.005 & Small mammal & 14 & 1,275 & 27.1 \\
\hline
\end{tabular}

a. Tracks were identified to the finest possible taxon and potential species for the study area were based on Forrest (1988); Abr shows abbreviations used in Figures; asterisks indicate uncommon species that were not individually analysed. 
5 b. Weights obtained from (Harestad \& Bunnel 1979). Functional groups were based on body weight and diet; "small mammals" combines small herbivores and shrews, as the prey of larger predators.

c. Total number of tracks recorded (approaches(A)+crossings $(C)+\operatorname{travels}(\mathrm{D}))$

8 d. Average on-transect track distance $(8 \mathrm{C}+\mathrm{D}) \mathrm{m}$ per km surveyed; averaged across 28 transects, each surveyed 9 times; the total distance surveyed was $252 \mathrm{~km}$ (9 surveys X 14 sites X 2 transects X $1 \mathrm{Km})$. 


\section{Figure 1}

Example of site layout showing a typical landscape context, transect layout and three types of mammal movements recorded by this study.

Example of a study site layout: (a) shows a typical landscape context and the paired seismic line (SL) and forest transects; (b) diagrams the transect details, including their division into $10,0.1 \mathrm{~km}$ sub-transects and the three types of individual movement (approaches, crossings or travels). 
a.

므 Transect

Road

Seismic line

= Pipeline

Forest

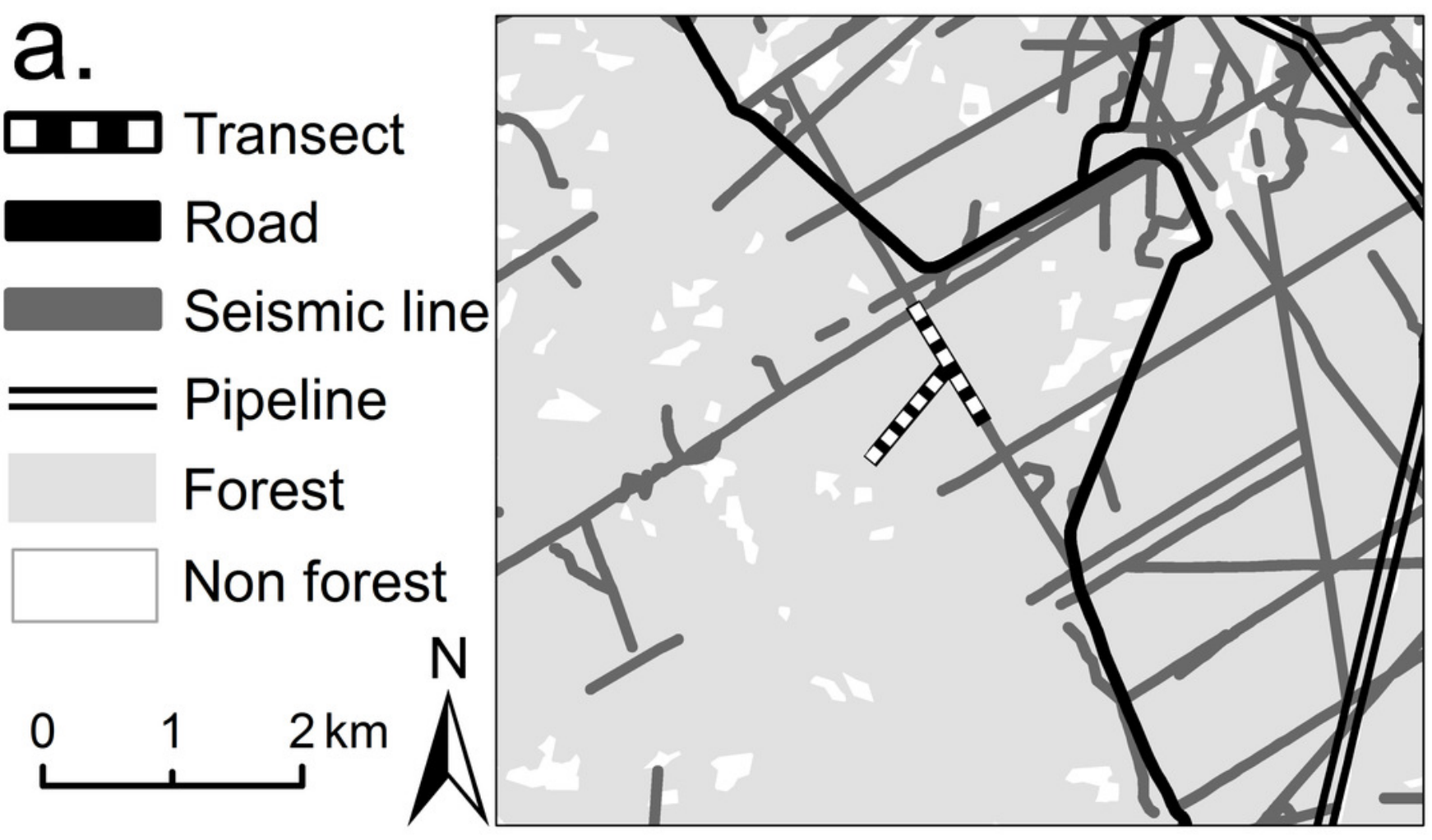

b. Seismic line

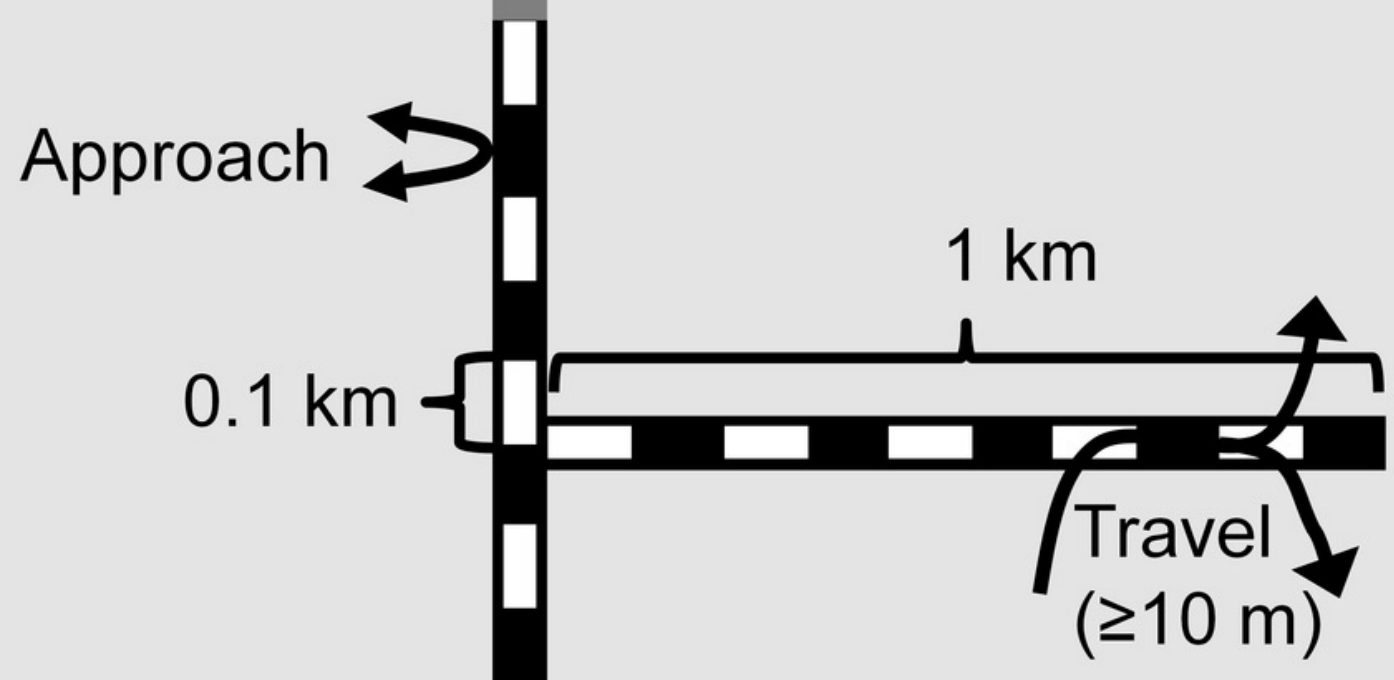

Crossing 


\section{Figure 2 (on next page)}

Comparison of mammal crosswise movement, linear movement and habitat use, between seismic line clearings and forest habitat for different species.

Comparison of mammal movement and habitat use between seismic line (SL) clearings and forest habitat for different species. (a) Crossing propensity (\% of transect approaches which fully crossed), (b) Linear travel propensity (\% of track length which was linear along the transect), (c) Habitat usage intensity (total on transect track extent). Species are ordered by body size-diet group (see Table 1 for abbreviations): large predator (L pred), mid-sized predator (M pred), large herbivore (L herb), mid-sized herbivore ( $M$ herb), small mammal (S mam). Values are means and standard errors ( $n=14$ paired transects per habitat), with results declared significant by Benjamini-Hochberg (BH) procedure and paired t-test $P$-values (unadjusted, $* P<0.05, * * P<0.01, * * * P<0.001$ ). Results declared non-significant by $\mathrm{BH}$ procedure and unadjusted $P<0.1$ indicated by + (Supplementary Tables 8, 9, 10). 
PeerJ

Manuscript to be reviewed

a.

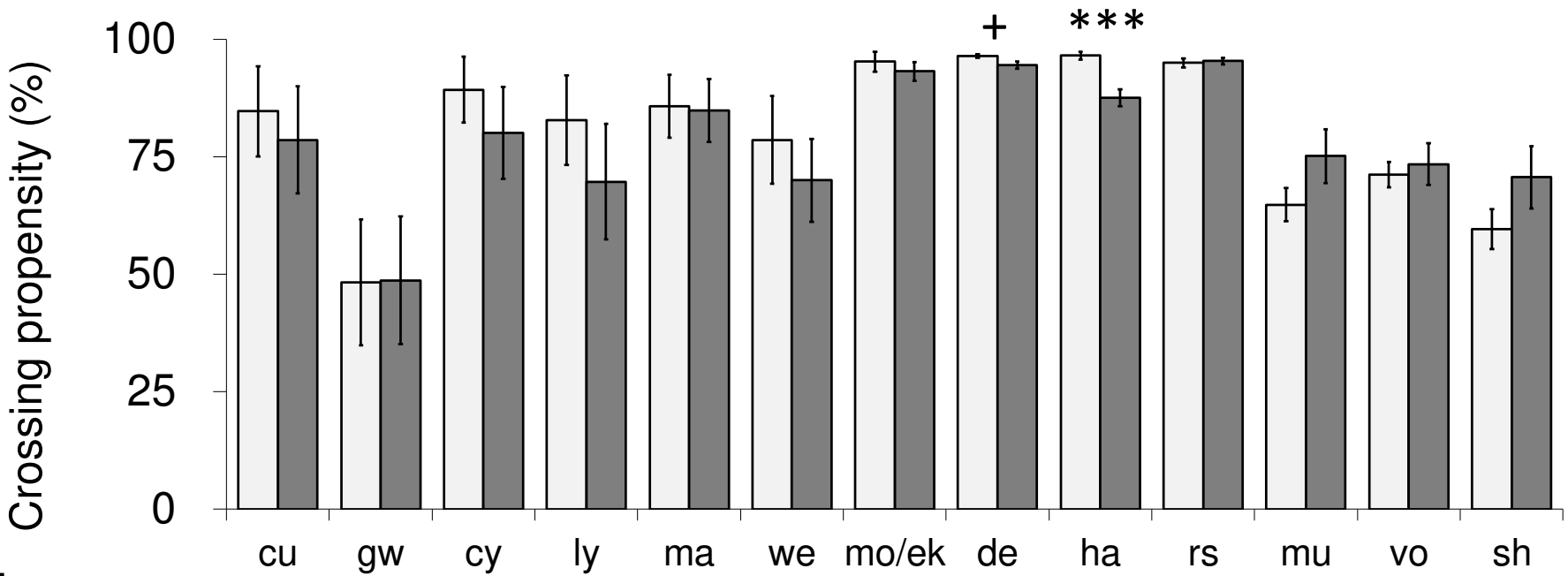

b. 100
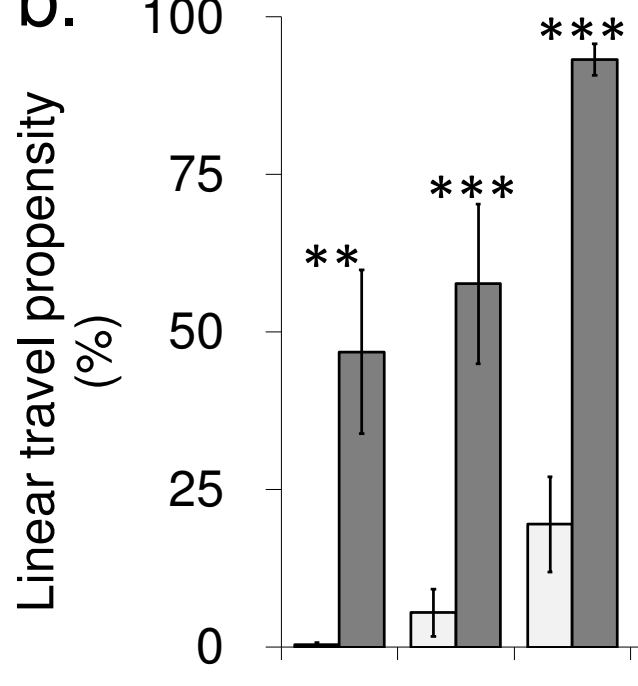

C. 800

cu gw cy ly ma we mo/ek de ha rs mu vo sh
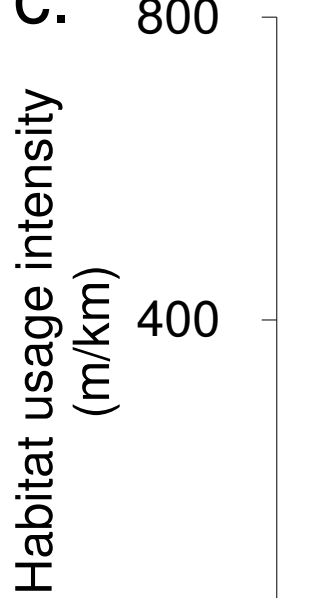

$\square$ Forest $\square$ Seismic line 


\section{Figure 3 (on next page)}

Comparison of mammal crosswise movement, linear movement and habitat use, between seismic line clearings and forest habitat for functional groups based on body size-diet combinations.

Comparison of mammal movement and habitat use between seismic line (SL) clearings and forest transects for different body size-diet groups: large predator ( $L$ pred), mid-sized predator ( $\mathrm{M}$ pred), large herbivore ( $\mathrm{L}$ herb), mid-sized herbivore ( $\mathrm{M}$ herb), small mammal (S mam). (a) Crossing propensity (\% of transect approaches which fully crossed), (b) Linear travel propensity (\% of track length which was linear along the transect), (c) Habitat usage intensity (total on transect track extent for multiple species recorded simultaneously). Values are means and standard errors ( $n=14$ paired transects in forest and SLs), with results declared significant by Benjamini-Hochberg $(\mathrm{BH})$ procedure and paired t-test $P$-values (unadjusted, $* P<0.05, * * P<0.01, * * * P<0.001$ ). Results declared non-significant by $\mathrm{BH}$ procedure and unadjusted $P<0.1$ indicated by + (Supplementary Tables $8,9,10$ ). 
a.

ते 100

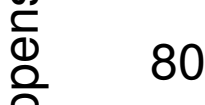

흥 60

兵 40

บे 20

0

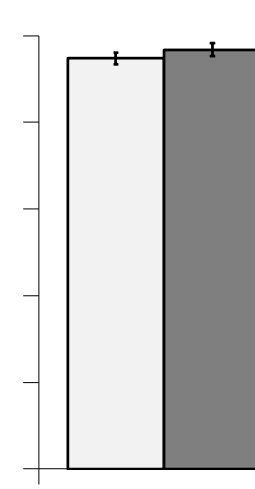

L pred

$\square$ Forest $\square$ Seismic line

b.

b. 100

....

$\begin{array}{ll}\frac{2}{0} & 80 \\ \frac{0}{0} & \\ \frac{0}{0} & 60 \\ \frac{0}{2} & \end{array}$

80

60

$\frac{0}{\circ} \stackrel{0}{\circ}$

$\stackrel{\pi}{=}$

ब 20

$\stackrel{\Phi}{5}$

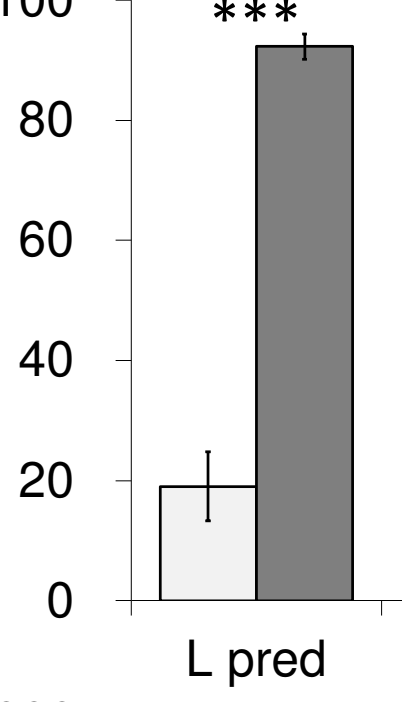

L pred
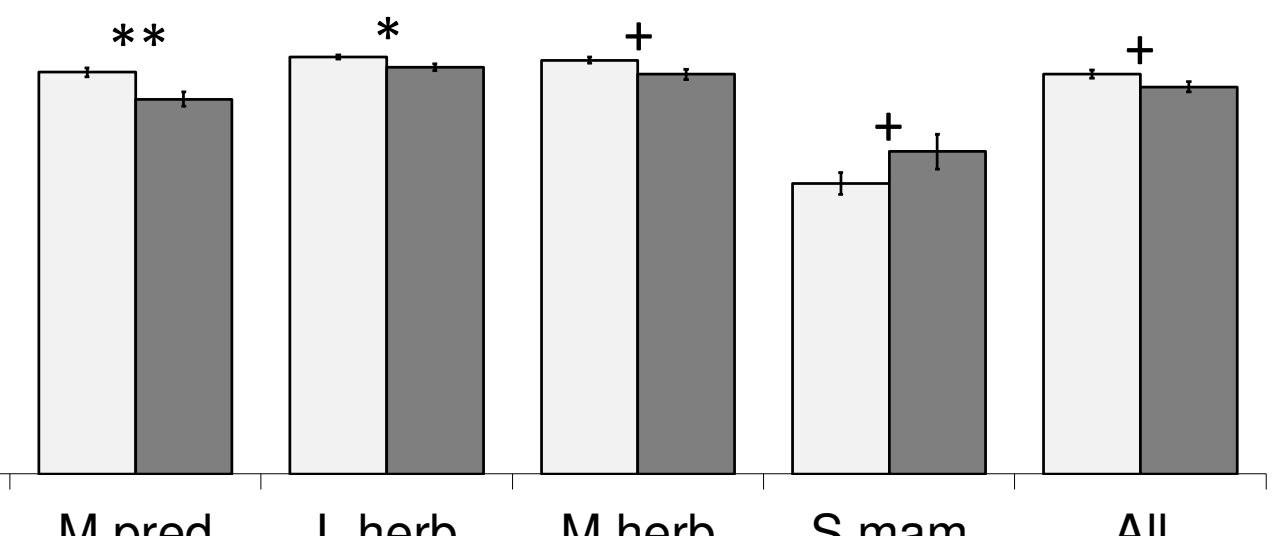

All

C. 2,000
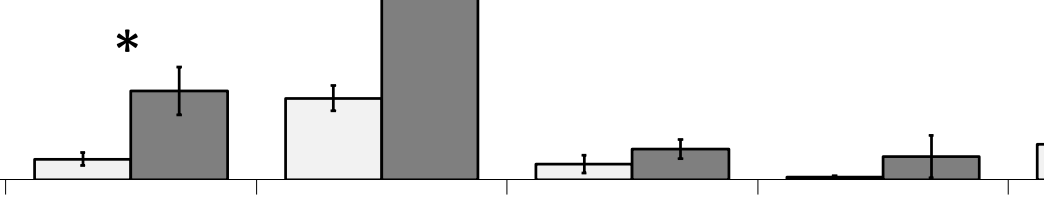

$* * *$

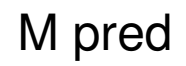

$\mathrm{L}$ herb

$\mathrm{M}$ herb

S mam

All
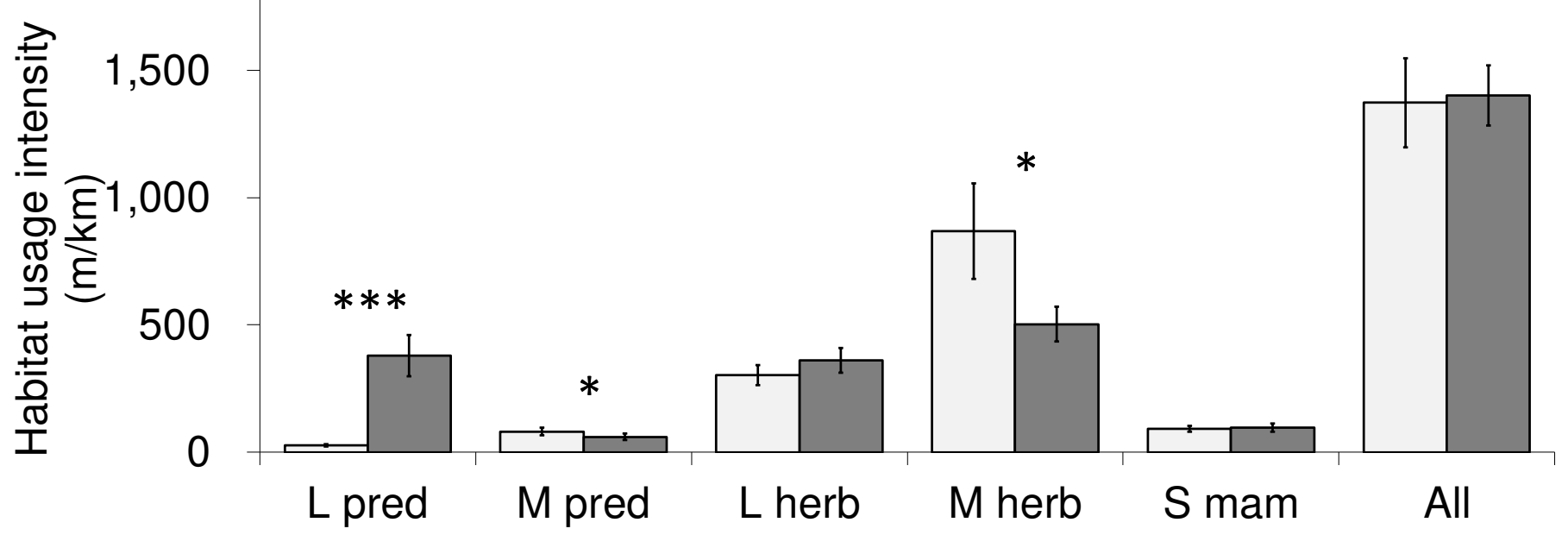


\section{Figure 4 (on next page)}

Effect of proximity to seismic line clearings on forest habitat usage intensity by affected mammals.

Mean moose (a) and shrew (b) habitat usage intensity (meters of track per sub-transect, standard error) within $100 \mathrm{~m}$ sub-transects which were located in forest, at various distances from the nearest seismic line. Results of repeated measures ANOVA where forest subtransects within sites (subjects, $\mathrm{N}=14$ ) were measured repeatedly (10 sub-transects per site) and classified by distance to the nearest seismic line (0-50 m ( $n=36$ sub-transets); 51-150 m $(n=44) ; 151-570 m(n=60))$, to assess the effect of distance to $S L$ on habitat usage intensity $(* P<0.05)$. Refer to Supplementary Table 4 for results for all mammals analyzed. 
a. Moose/elk*

b. Shrew
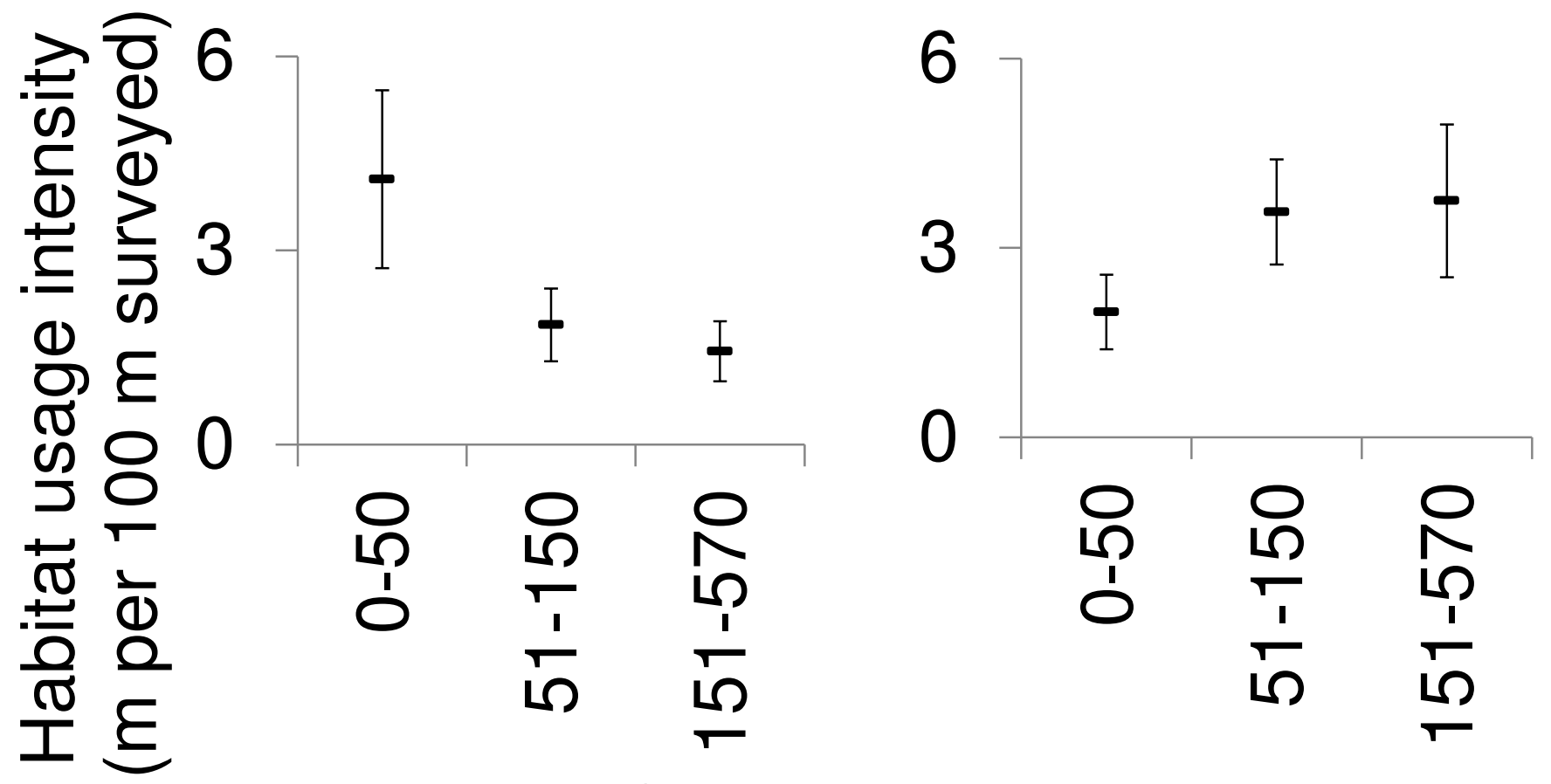

Distance from seismic line edge $(\mathrm{m})$ 